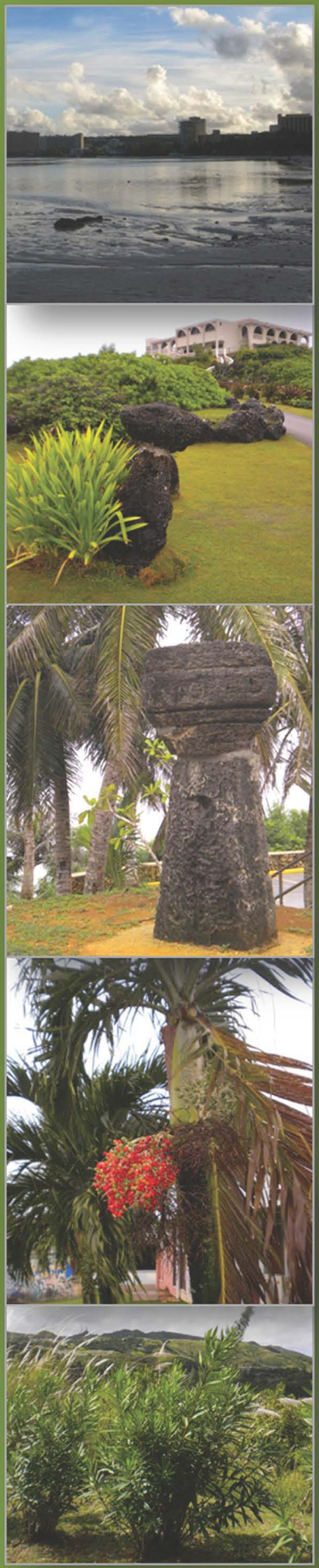

\title{
Guam Energy Action Plan
}

Misty Dawn Conrad and J. Erik Ness

Sponsored by the Department of the Interior Office

of Insular Affairs and the Guam Energy Task Force

\section{July 2013}

Produced under direction of the U.S. Department of the Interior Office of Insular Affairs by the National Renewable Energy Laboratory (NREL) under Interagency Agreement IAG-10-1773 and Task No. WFF41010

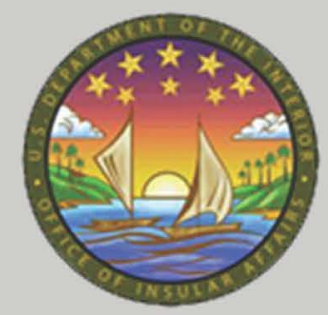




\author{
Prepared and facilitated by Misty Dawn Conrad and J. Erik Ness \\ of the National Renewable Energy Laboratory \\ under the guidance of the Guam Energy Task Force
}

\begin{abstract}
ACKNOWLEDGMENTS
The National Renewable Energy Laboratory (NREL) thanks the U.S. Department of the Interior's Office of Insular Affairs (OIA) and the Guam Energy Office (GEO) for providing funding for this effort. In particular, NREL would like to thank OIA Assistant Secretary Eileen Sobeck and GEO Administrator Peter Calvo for their vision and leadership in moving the energy planning process forward in the Pacific Territories.
\end{abstract}

NREL would like to acknowledge the valuable assistance of OIA staff: Director Nikolao Pula, Angela Williams, and Mark Brown.

NREL would also like to thank Governor Eddie Calvo for his support in the creation of this energy action planning document and the ongoing energy transformation efforts in Guam.

In addition, the following individuals should be acknowledged for their roles in helping develop, review, and finalize this energy action plan:

- Guam Energy Task Force: Members are listed in Appendix A.1.

- NREL: Kari Burman, Caley Johnson, John Nangle, Judy Powers, Sheila Hayter, and Stephanie Savage

\title{
NOTICE
}

This manuscript has been authored by employees of the Alliance for Sustainable Energy, LLC ("Alliance") under Contract No. DE-AC36-08GO28308 with the U.S. Department of Energy ("DOE”).

This report was prepared as an account of work sponsored by an agency of the United States government. Neither the United States government nor any agency thereof, nor any of their employees, makes any warranty, express or implied, or assumes any legal liability or responsibility for the accuracy, completeness, or usefulness of any information, apparatus, product, or process disclosed, or represents that its use would not infringe privately owned rights. Reference herein to any specific commercial product, process, or service by trade name, trademark, manufacturer, or otherwise does not necessarily constitute or imply its endorsement, recommendation, or favoring by the United States government or any agency thereof. The views and opinions of authors expressed herein do not necessarily state or reflect those of the United States government or any agency thereof. 


\section{DOCUMENT OVERVIEW}

This document describes the four near-term strategies selected by the Guam Energy Task Force during action planning workshops conducted in March 2013, and outlines the steps being taken to implement those strategies.

Each strategy addresses one of the energy sectors identified in the Guam strategic energy plan as being an essential component of diversifying Guam's fuel sources and reducing fossil energy consumption $20 \%$ by 2020 (20x20) - see figure 1 , below.

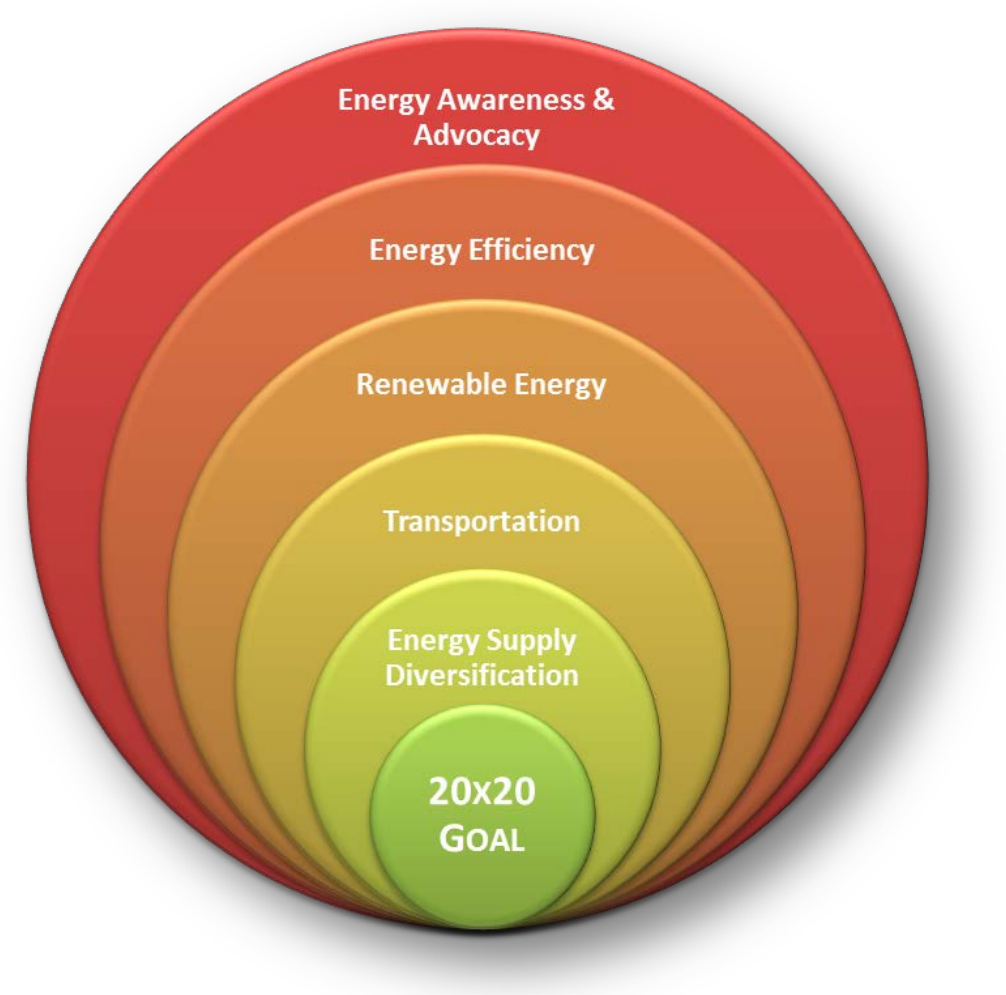

Figure 1. Options for reaching Guam's $20 \times 20$ Goal, as identified in the strategic energy plan

The four energy strategies selected are:

1. Expanding public outreach on energy efficiency and conservation

2. Establishing a demand-side management revolving loan program

3. Exploring waste-to-energy options

4. Influencing the transportation sector: anti-idling legislation, vehicle registration fees, and electric vehicles 


\section{TABLE OF CONTENTS}

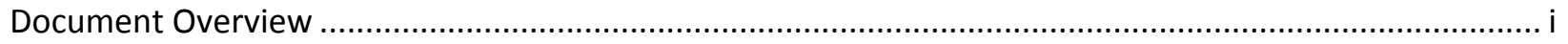

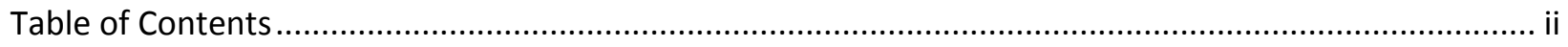

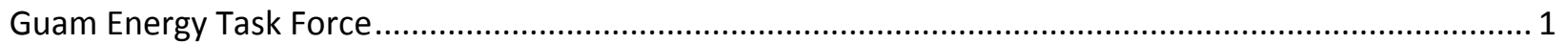

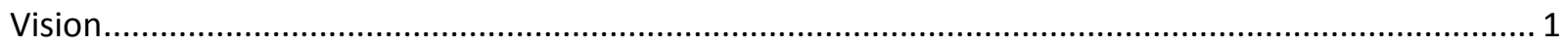

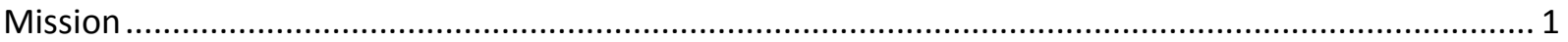

GETF Organizational Structure and Subcommittee Objectives ........................................................ 1

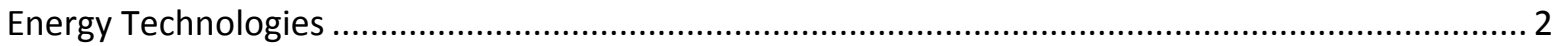

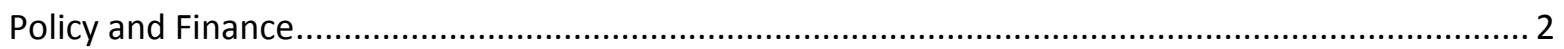

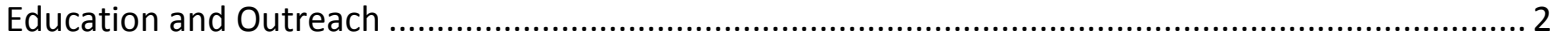

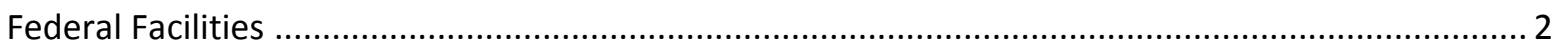

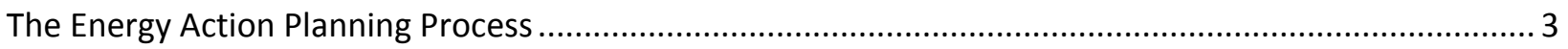

Strategy 1. Public Outreach on Energy Efficiency and Conservation..................................................... 4

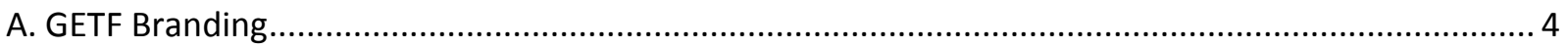

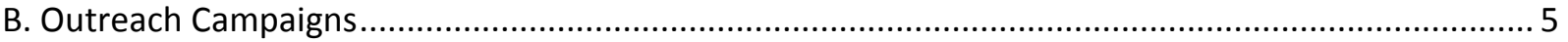

Strategy 2. Demand-Side Management Revolving Loan Program......................................................... 7

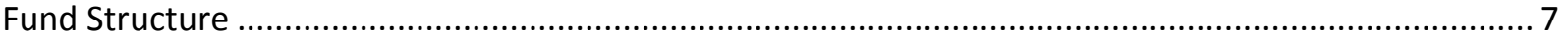

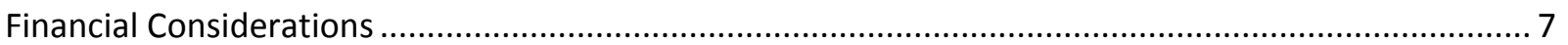

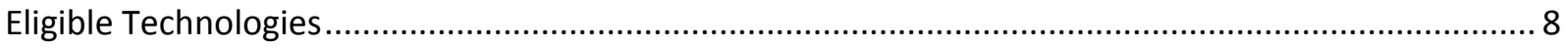

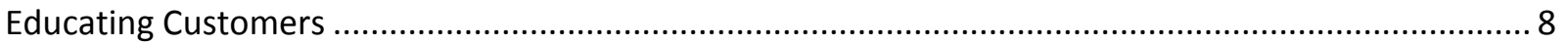

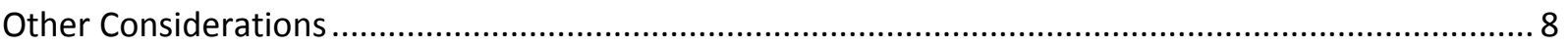

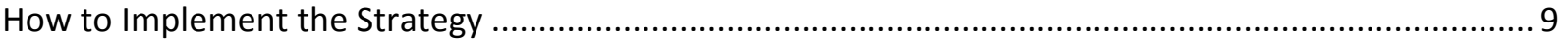

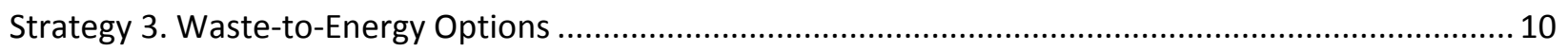

A. Investigate Guam's Existing Waste-to-Energy Legislation............................................................ 10

B. Review the Status of Waste-to-Energy Power Generation Technologies ....................................... 11

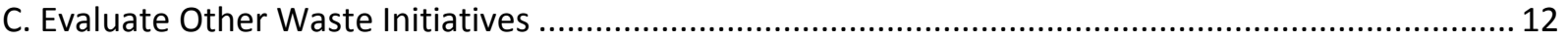

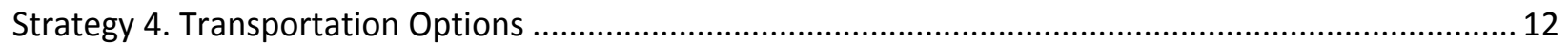

A. Implement Anti-Idling Legislation to Stop Heavy Vehicles from Wasting Fuel ................................. 13

B. Investigate the Pricing Structure for Vehicle Registration Fees ..................................................... 14

C. Examine the Feasibility of Bringing Electric Vehicles to Guam .................................................... 15 


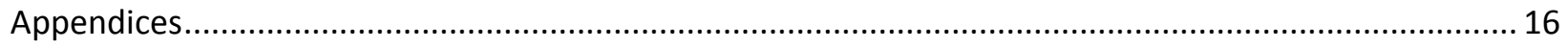

A.1. Guam Energy Task Force Members and Other Contributors to the Action Plan ......................... 16

A.2. Fossil Fuel Consumption Scenarios: Wedge Analysis ............................................................... 19

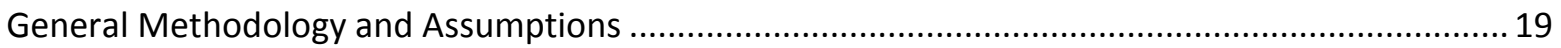

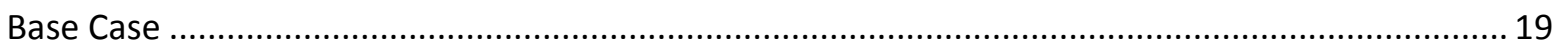

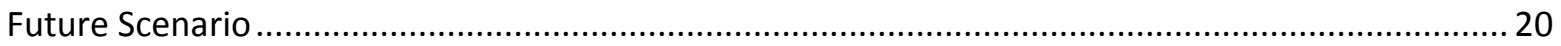

Methodology and Assumptions for the Future Scenario............................................................. 22

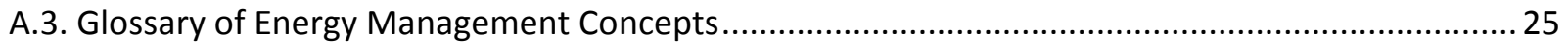

iii | P a g e 


\section{GUAM ENERgY TASK FORCE}

The Guam Energy Task Force (GETF) was established by Executive Order 2010-15 on May 10, 2010.

Vision

A secure, sustainable, and economically prosperous future for Guam.

\section{Mission}

As stated in Executive Order No. 2010-15, GETF's mission includes the following objectives:

- Reduction of reliance and expenditures on fossil fuels

- Development of indigenous and renewable energy sources

- Improvement of energy generation infrastructure

- Resource preservation, restoration and enhancement

- Training and education regarding energy efficiency and conservation

- Development of funding and financial strategies for sustainability and economic development

- Engagement in national and regional efforts to address island energy concerns

- Develop funding and financial strategies for sustainability and economic development

- Engage in national and regional efforts to address island energy concerns

- Support energy literacy curriculum in all educational institutions

- Develop a vision, mission and goals for reducing dependence on fossil fuels, improving energy efficiency, and developing renewable energy resources

- Establish an organizational structure to appropriately develop a comprehensive, long-term strategic energy plan for Guam

\section{GETF Organizational Structure and Subcommittee Objectives}

The GETF is led by an Executive Committee with four subcommittees: energy technologies, policy and finance, education and outreach, and federal facilities (figure 2). The GETF is a nonregulatory advisory group sponsored by the current administration. The GETF is comprised of local volunteers from multisector stakeholder communities and supported by federal agencies.

Convened in September 2010, the GETF recruited appropriate leaders for membership to ensure diverse and equitable representation. It facilitated a transition toward a more sustainable energy future that will utilize the island's natural resources. The GETF is a forum for considering options and offering guidance related to the achievement of the island's energy goals. 


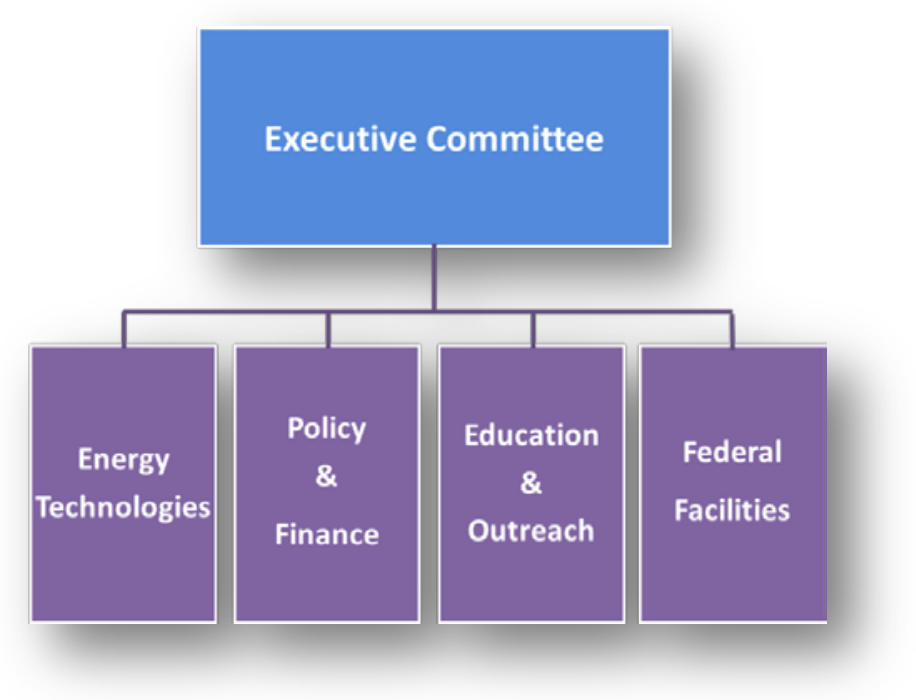

Figure 2. GETF organizational structure

The four subcommittees and their focuses are described below.

\section{Energy Technologies}

The Energy Technology Subcommittee is focused on assessment and deployment of cost-effective energy efficiency and renewable energy opportunities. This includes conservation strategies, efficient building design, facility- and utility-scale renewable energy technologies, grid integration, and transportation.

\section{Policy and Finance}

Governmental policy is foundational to reshaping the regulatory landscape to clear the way for a new energy future. The Policy and Finance Subcommittee assists lawmakers and other clean energy advocates in analysis and development of policy opportunities to promote implementation of energy efficiency and renewable energy.

\section{Education and Outreach}

The Education and Outreach Subcommittee is focused on identifying and developing educational tools and programs needed to develop and advance a clean energy economy. This includes formal and informal programs spanning community outreach and education, technical and vocational training, and certification and degree programs.

\section{Federal Facilities}

In an effort to share information and facilitate dialogue, representation from the DOD has been essential. This subcommittee has been in full swing responding to federal mandates. It concentrates on conservation, meter and building efficiency, outreach, and renewable energy and alternative vehicles. 


\section{The Energy Action Planning Process}

In 2008, record high oil prices focused attention on the need to develop alternatives to Guam's near$100 \%$ reliance on imported fossil fuels. Due to its geographic isolation, nonrenewable resources are extremely limited and subject to large volatility in pricing and availability. Guam recognized that creating energy security is key to its future economic development and sustainability, and that proper long-term planning is required to achieve energy security.

In March of 2010, the U.S. Department of the Interior (DOI) Office of Insular Affairs (OIA) sponsored a regional energy meeting in Golden, Colorado, that included Guam, the CNMI, and American Samoa. Guam delegates met with representatives from the U.S. Department of Energy (DOE) and senior principals from DOE's National Renewable Energy Laboratory (NREL) to discuss ways to improve energy efficiency and increase the deployment of renewable energy technologies in the Pacific. As a result of this meeting, the Governor of Guam established an energy task force to help coordinate energy policy and promote long-term planning.

In the summer of 2010, OIA funded NREL to conduct an initial technical energy assessment for Guam ${ }^{1}$ that detailed energy consumption and production data to establish an energy baseline. This assessment was used to conduct an energy analysis that estimated the energy efficiency and renewable energy potential for Guam.

The Guam Initial Technical Assessment Report was published in April 2011, and was used by the GETF as the starting point for developing the Guam Strategic Energy Plan, which was completed in 2012 and formally adopted in March 2013.

With continued funding from OIA and with the support of NREL staff, the GETF conducted action planning workshops in March 2013 to identify the near-term strategies that would be likely to have the greatest impact on reducing Guam's fossil-fuel energy consumption. Those strategies are described in detail in this document.

Unlike the strategic energy plan, which established the overall long-term goals for energy consumption and generation in Guam, this action plan selects a handful of specific strategies that are achievable in the short term (1-3 years), breaks those strategies down into feasible incremental steps, identifies the stakeholders and desired outcomes, identifies the organizations and individuals responsible for implementing the actions, and sets a timeline for each step.

When evaluating technology options, the GETF focused on mature, proven energy efficiency and renewable energy technologies that are commercially available and financially viable today.

Care was taken to ensure that the actions selected were not duplicating existing efforts, and that they leveraged work in other agencies and organizations as much as possible. The task force also gave

\footnotetext{
${ }^{1}$ Ian Baring-Gould et al., Guam Initial Technical Assessment Report. National Renewable Energy Laboratory, NREL/TP-7A40-50580, April 2011.
}

3| P a g e 
considerable thought to ways of measuring the impact of the strategies in terms of reductions in fossil fuel consumption.

This action plan is a living document that will be regularly updated by the task force. Programs and strategies will be modified or replaced as the task force gathers new information about different approaches to reducing energy consumption and as new technologies for generating electricity and reducing transportation fuel consumption emerge, or existing, but previously impractical, technologies become commercially viable.

During deliberations at several action planning workshops held in March 2013 and a follow-up discussion in April, group consensus was reached on the four strategies described in the following pages.

\section{Strategy 1. Public Outreach on Energy Efficiency and Conservation}

Energy awareness and outreach is one of the strategies from the strategic plan that was identified as having the greatest potential impact on energy consumption in Guam.

In order for the GETF's outreach campaigns to be have maximum impact, it is important for the GETF to be perceived by the citizens of Guam as a voice of authority. This involves raising awareness of the GETF and its role in tandem with energy education initiatives as this will maximize the impact of those initiatives.

\section{A. GETF Branding}

The GETF was envisioned as an independent organization that would carefully and methodically evaluate options for change, provide accurate information to the public, encourage changes in behavior, and recommend policy changes that could help ensure future energy security for Guam. Accomplishing these goals requires a hands-on approach, with the GETF helping to implement the solutions it recommends, working in collaboration with businesses, public sector agencies and the military.

The benefit of GETF branding is that, if the GETF has a strong identity as an independent authority, it can help to legitimize, strengthen and lend credibility to the energy outreach messages of other organizations, leveraging existing expenditures on energy and environmental education being carried out by other entities. It also benefits any smaller organizations that partner with the GETF, as they will get greater exposure through association with the GETF.

Existing organizations/initiatives that the GETF can partner with include:

- Guam Energy Office (GEO) - There is a direct relationship between recycling and energy use. GEO recently handed out recycling bins with this message on the side: "Recycling saves energy."

- Green Dream - Part of the Island-wide Beautification Task Force (IBTF), which is a very successful campaign.

- The i*recycle program.

- The University of Guam (UOG) Center for Island Sustainability (CIS) Energy Education.

\section{4 | P a g e}


The intention is not to be exclusive, rather for partner organizations to leverage each other's visibility in the eyes of the target audiences, promoting initiatives through joint messaging, such as "GETF in conjunction with the Green Dream ..."

\section{Responsible for coordinating implementation: $\quad$ GEO and UOG's CIS}

\section{Potential challenges}

The branding itself is not a challenge. There is plenty of marketing talent on-island, including private companies and in-house designers and campaign staff at UOG. The only potential obstacle is covering the costs of developing the brand, which are not expected to be high.

\section{Specific actions and timeline}

1. Develop a work plan outlining the sequence of activities to accomplish this task, estimate the likely costs, suggest potential sources of funding and identify potential resources needed. The Education and Outreach Subcommittee will finalize the draft work plan and present it at the GETF meeting on June 14, 2013 for discussion and adoption. [Education and Outreach Subcommittee, Carl

\section{Swanson]}

2. Secure funding (including first leveraging the resources of GETF members' organizations, such as UOG), and then issue an RFP for an existing marketing company to work with the GETF to implement the strategy if needed. [Education and Outreach Subcommittee, Carl Swanson]

3. Create a GETF website that provides information on the GETF and outreach campaigns. This could be started before the GETF has its own branding or campaigns, with the website acting as a portal with links to information about existing campaigns, GPA webpages describing rebates and incentives, etc. It would help establish the GETF as a source of information about energy in advance of its official "launch." The Guam Community College (GCC) may be able to help set up this website.

\section{Reporting on progress and measuring impact}

Carl Swanson will report progress at the general GETF meeting scheduled for June 14, 2013.

\section{B. Outreach Campaigns}

Outreach campaigns will focus on promoting energy conservation (not using energy by doing without some service, such as turning the lights off) and energy efficiency (using less energy to accomplish the same task, such as using light bulbs that require less electricity) as it costs less to reduce energy consumption than it does to supply more energy using renewable or other technologies.

GEO is an important partner in this work as it has experience with implementing outreach campaigns, as is UOG, which has the existing skill set to measure the impact of those campaigns.

Before the GETF undertakes any outreach campaigns, it will identify existing campaigns and evaluate their effectiveness. The GETF's intention is, as much as possible, to be a clearinghouse for information that others are producing, only creating its own information when it identifies a gap. Part of developing any new campaign will be to consider how to maximize the impact of the campaign using carefully targeted messaging to energy consumers and children, who in turn can influence their parents. 
Possibilities for new information campaigns include:

- Tips on energy conservation.

- Helping people understand that efficiency improvements can mean spending less on their electric utility bills (which in turn means less power generation and less pollution). This could include promoting internet-based tools that can provide a cost-benefit analysis for the purchase of energy efficient technologies.

- Public service announcements (PSAs) on how to get the most out of the smart meters being installed by the Guam Power Authority (GPA) .

- Information on rebates for appliances and other energy-related investments (e.g., cool roofs) as they become available.

\section{Responsible for coordinating implementation:}

\section{GEO and UOG's CIS}

\section{Potential challenges}

Possible challenges include:

- Securing funding and ensuring the long-term sustainability of funding to cover the time and expense involved in running information campaigns.

- Ensuring consistency of messaging among organizations involved in energy campaigns: GETF, GPA, GEO, CIS, and others.

- Ensuring that sources of information used by the GETF and partners are both reliable and "Pacificcentric" so that the messages are relevant to audiences in Guam.

- Ensuring that outreach messages actually engage the average citizen.

\section{Specific actions and timeline}

1. Collect information on existing energy efficiency and conservation outreach initiatives. [Peter Calvo with input from Peggy Denney and Heidi Ballendorf]

2. Integrate Service Learning into the education strategy as a gateway to address K-12 education.

3. Identify metrics that could be used to measure the impact of the outreach initiatives, such as conducting surveys either on line or at events.

4. Develop a list of specific outreach messages and programs to be discussed and evaluated by the GETF. This will be done after information on existing initiatives is collected.

5. Create a GETF website that could act as a portal with links to information about existing campaigns, GPA webpages describing rebates and incentives, etc. This is the same website described under task 1.A.3, above.

6. Create opportunities for people to provide feedback and input on the outreach initiatives and ask questions. This could include an on-line blog, a cell phone app, and use of social media. Responsibility for this task will be determined after the GETF website is established. 


\section{Reporting on progress and measuring impact}

GEO and CIS will report progress at the general GETF meeting scheduled for June 14, 2013.

Identifying suitable metrics is one of the action items listed above.

\section{Strategy 2. Demand-Side Management Revolving Loan Program}

Energy-saving investments are very effective because people communicate their savings (from, for example, installing more-efficient air conditioners) to their neighbors and friends. Existing rebate programs have led to accelerated sales in efficient air conditioners in Guam, but efficient air conditioners are very expensive, and the demand for rebates for these and other technologies is always greater than the supply. There is also a risk that companies that honor the rebates will raise their prices during the duration of the rebate program.

Rebate programs can be useful but have limited impact and are not sustainable. Another alternative that can be developed in parallel with rebate programs is to establish a revolving loan fund (RLF) that can continue in perpetuity because it is financially self-sustaining.

Demand-side management (DSM) revolving loan programs allow electricity customers to borrow money to purchase energy-efficient appliances or pay for other energy-saving measures, such as weatherization improvements or cool roofs. The fund is repaid over time, typically out of the money saved by those customers on their utility bills. This allows the fund to make additional loans to other customers.

\section{Fund Structure}

There are several ways to structure an RLF, including the following.

- The utility company can lend the money and require customers to keep paying the same monthly bill or add a small premium to the bill, even though their consumption of electricity is lower, until the loan is paid off.

- An independent entity can lend the funds, with the utility company repaying the lending entity through savings on a customer's utility bill.

- A financial institution can establish a line of credit specifically for energy-saving measures, with customers being required to make regular payments until their loan is paid off. This option has two disadvantages: (1) customers with low credit scores tend to be excluded unless another entity offers to be a loan guarantor, and (2) these funds tend to be more expensive to administer due to the higher cost of recovering unpaid debts.

\section{Financial Considerations}

There are a variety of other financial considerations involved with setting up an RLF, such as ensuring that the program maintains a minimum level of funds in the bank in order to accrue interest, which can then be used to cover fund administration expenses and bad debts. 
It is a good idea to set a dollar limit for the loan based on an individual's creditworthiness (FICO score) and customer payment history (from GPA records). Setting an overall dollar limit per individual will prevent people who own multiple properties, such as apartment complexes, from cornering the market.

\section{Eligible Technologies}

There are also technology considerations with setting up a DSM RLF. It is a good idea to limit eligible technologies, requiring customers to choose from a preapproved list of technologies. Guam's DSM RLF could be implemented in phases, with the first phase providing loans only for those technologies that are relatively inexpensive and provide a quick return on investment, such as cool roofs, weatherization improvements, and two-pane windows.

The second phase could include more expensive equipment and appliance purchases, such as solar hot water systems and efficient air conditioners and refrigerators. Installations of larger equipment such as roof-mounted solar hot water systems also incur the expense of ensuring that the installation meets safety standards and building codes.

Structuring the RLF in this way has the benefit of ensuring that more people can tap into the fund at its inception.

\section{Educating Customers}

A well-designed DSM RLF also includes an education component. As an example, customers with cool roofs need to understand the importance of regularly sweeping their roofs to prevent them from darkening and thereby reducing the energy savings resulting from the investment. Periodic inspections by a third party can help to ensure that maintenance requirements are met.

Many customers would benefit from having energy conservation "best practices" explained to them. This aspect of the DSM RLF could be combined with the energy awareness outreach program described under strategy 1.

\section{Other Considerations}

There are other issues to consider when developing an RLF, such as whether to structure the program so that renters can take advantage of it in addition to homeowners. This could include requiring additional guarantees or collateral in order to mitigate the higher risk of lending to renters, as well as limiting their technology choices. Efficient appliances can move with the renter, whereas cool roofs can't.

It can be a good idea to include information on the electric utility bill that helps customers to see the impact of their energy-saving purchase on their monthly bill, such as including the amount of electricity consumed in the same month of the previous year. This makes it easier for people to see how much their power bill has dropped. In Guam, water bills currently include information on past consumption but electricity bills do not.

\section{8| P a g e}




\section{How to Implement the Strategy}

\section{Responsible for coordinating implementation:}

\section{GEO (Peter Calvo) and GPA (Joaquin Flores)}

GEO is the primary lead for technology options.

GPA will do the data mining on a potential recipient's ability to pay (as it has existing customer delinquency records) and will be the enforcer of last resort, as it can disconnect customers who fail to meet their repayment obligations.

Both organizations will work in tandem to investigate sources of funding for implementing this strategy.

\section{Potential challenges}

- Some revolving loan funds have failed. The fund's sustainability is essential. It is important to apply best practices when designing the program.

- Securing financing for technical advisors and to seed the revolving loan fund itself.

- Ensuring that inefficient equipment is disposed of. When someone purchases a new efficient air conditioner or refrigerator, they have a tendency to want to keep the old unit, which can increase their overall energy use. This can be overcome by making sure the old unit is decommissioned, for example by requiring that it is picked up by an authorized collection company or properly recycled in compliance with EPA regulations for scrap metal (with proof of disposal required).

\section{Specific actions and timeline}

1. Identify a source of expert advice - A third party needs to provide assistance on how to structure the loan fund.

2. Identify a source of funding for the advisors - OIA is not an option but DOE may be able to help.

3. Identify a source of funding for the loan program - Approach DOE as it is supportive of RLFs.

4. Timeline - An RLF takes about a year to set up after funding is secured. After designing the program, it needs to be tested before it is rolled out.

5. Design an energy auditing program - Including the standards that will be used, the level of audit (probably just a level 1 "walk-through" audit), and the development of an education component. The auditing program can be designed while the revolving loan fund is being developed.

- The auditor can recommend "best practices" for people with poor energy-use habits and explain the bottom-line savings for changed behavior (e.g., "this is how much you will save if you turn off the air conditioner during the two hours it takes you to go to the store").

- It is important to capture existing behavior so that it is possible to measure the realized savings, which will encourage buy-in from the homeowners.

6. There are currently very few energy auditors in Guam. CIS has a program to train auditors but it is limited in scope. If NREL were engaged, it could help develop a "train the trainers" program tailored to Guam and the specifics of its housing stock. 


\section{Reporting on progress and measuring impact}

GEO and GPA will report progress at the general GETF meeting scheduled for June 14, 2013.

The impact of the program will be measured in terms of reduced energy use by participants in the RLF.

\section{Strategy 3. WASte-to-Energy Options}

Waste-to-energy (WTE) power generation could be useful on Guam because it provides baseload power and could make productive use of some of the trash that is currently disposed of in landfills. However, WTE development is a longer-term strategy because of existing legislative hurdles and the need to conduct waste characterization studies before the most appropriate WTE technology is chosen.

The GETF also supports waste reduction as a long-term strategy for Guam. Encouraging people to produce less waste conflicts with potential WTE power plant feedstock requirements, so these conflicting goals must be evaluated together.

Before exploring WTE options in more detail, the GETF decided that it is important to take the following actions.

\section{A. Investigate Guam's Existing Waste-to-Energy Legislation}

Public Law (PL) 25-175, which was adopted in December 2000, appears to restrict the development of WTE facilities in Guam.

For example, on page 3 of the document, it states: "No officer or agency of the government of Guam shall implement or expend funds, or commit resources to implement any portion of the Integrated Solid Waste Management Plan for the Island of Guam which is disapproved or deleted by this Act or any waste-to-energy facility, or any incineration project aimed at reduction of municipal solid waste."

The full text of the law is at: http://guamlegislature.com/Public Laws 25th/P.L.\%2025-175.pdf.

The GETF will investigate the original intent of the law, its current interpretation and the likelihood of clarifying or amending it to permit WTE facilities in Guam. It is believed that many legislators would like to see WTE projects on the island, so there may be willingness to overcome this apparent obstacle to development.

GETF members will have meetings with legislators (including the legislators who originally sponsored PL 25-175), the EPA (to ascertain their current working definition of WTE), and the federal judge who would adjudicate any challenge to PL 25-175. Other legislation that may impact WTE development will also be investigated.

Responsible for coordinating implementation:

Senator Ada's office (Cyrus Luhr)

\section{Potential challenges}

No challenges are anticipated as this strategy is investigative in nature, requiring an investment of time but no direct financial outlay.

10 | P a g e 


\section{Specific actions and timeline}

1. Ask EPA's lawyers how they define waste-to-energy in general and incineration in particular.

2. Ask some of the senators who authored/supported PL 25-175 what their intent was.

3. Summarize the potential legislative barriers to WTE arising from these conversations (as part of task 3.B.2 below).

4. Formulate a legislative action plan to overcome those barriers.

\section{Reporting on progress and measuring impact}

Cyrus Luhr will report progress at the general GETF meeting scheduled for June 14, 2013.

As this strategy is purely investigative in nature, it will not have any impact on fossil energy consumption. It could, however, lead to energy projects depending on the outcome of the investigation.

\section{B. Review the Status of Waste-to-Energy Power Generation Technologies}

WTE power generation encompasses a wide variety of technologies, including anaerobic digestion of organic wastes and sewage, landfill gas (methane) capture, direct combustion (incineration), cofiring with other fuels (such as biomass or coal), gasification (to produce a combustible gas), and pyrolysis (producing bio-oils that can be used to generate electricity). Not all of these technologies are equally viable or appropriate for Guam.

The GETF will investigate the various WTE technologies with possible assistance from NREL.

\section{Responsible for coordinating implementation: Cyrus Luhr}

\section{Potential challenges}

OIA does not have funds to support this task as it has already committed its technical assistance (TA) funds for Guam to other projects. However, this is not a significant obstacle, as this strategy is about investigating options, which can be done at very little cost.

\section{Specific actions and timeline}

1. Obtain information on WTE technology options and summarize this information in a report to the GETF. NREL will help with this activity.

2. Prepare a briefing document for legislators: (1) describing existing legal barriers to the adoption of WTE in Guam with background information on how these barriers came about (see task 1.A.3 above), and (2) a summary of those WTE technologies that are most applicable in Guam.

\section{Reporting on progress and measuring impact}

Cyrus Luhr will report progress at the general GETF meeting scheduled for June 14, 2013.

As this strategy is purely investigative in nature, it will not have any impact on fossil energy consumption. It could, however, lead to energy projects depending on the outcome of the investigation. 


\section{Evaluate Other Waste Initiatives}

The GETF will gather information on other waste-related initiatives and issues, including the following.

- The University of Guam's Center for Island Sustainability (CIS) is preparing to conduct a study that will examine what happens to waste in Guam. This waste stream study could help inform future decisions about the optimal WTE technologies to pursue.

- Possible synergies with, and impacts of, existing recycling/no littering campaigns, such as the i*recycle program.

- The potential impact of changes in the way the military disposes of its trash. Currently, the military is required to landfill all of its trash but that requirement will end in a few years.

\section{Responsible for coordinating implementation:}

\section{CIS and Edwin Reyes}

\section{with assistance from Peggy Denney}

\section{Potential challenges}

No challenges are anticipated as this strategy does not require any direct financial outlays.

\section{Specific actions and timeline}

1. Gather information on existing and planned waste/recycling initiatives in Guam and summarize this information in a report to the GETF.

2. If the legislative hurdles can be overcome, conduct an economic analysis of the leading technology options for Guam, including relative costs and benefits. NREL may be able to provide input into this analysis.

\section{Reporting on progress and measuring impact}

CIS will report progress at the general GETF meeting scheduled for June 14, 2013.

As this strategy is purely investigative in nature, it will not have any impact on fossil energy consumption. It could, however, lead to energy projects depending on the outcome of the investigation.

\section{StRATEgy 4. TRANSPORTATION OptIONS}

The GETF considered several changes that could cut fossil fuel consumption in the transportation sector, including various approaches to reducing miles traveled, improving the fuel economy of vehicles, encouraging the use of flex-fuel vehicles by using vehicle registration rebates, and introducing electric vehicles to Guam. After careful consideration, the task force decided to focus on the following nearterm tasks. Various other options will also be investigated by individual task force members, such as creating bus hubs with associated "park and ride" car parks. 


\section{A. Implement Anti-Idling Legislation to Stop Heavy Vehicles from Wasting Fuel}

Tour buses idle for hours to maintain cool conditions inside the vehicle, as the engine is required to provide power to the air conditioners. Two legislative solutions were discussed by the GETF.

1. Require tour companies to install auxiliary power units (APUs) on their buses as is being done by long-distance trucking companies on the mainland to prevent truckers from running their engines for hours when sleeping just to keep the air conditioners going.

- In the short term, APUs are more expensive than using extra fuel, but the EPA or another agency may be willing to subsidize part of the cost of the units.

- It may be possible to make a financial argument to the tour companies along with implementing the legislation. Investigate the bottom-line cost to a company of idling: what does an hour of idling time translate into in terms of miles traveled? For some vehicles, an hour of idling is equivalent to 50-60 miles of wear on the engine, which increases maintenance costs.

2. Implement a tax targeting tour bus companies and delivery trucks as a disincentive to idle.

- Possibly add a fee to tour company registration and define a threshold for idling. If a company can prove it has reduced its idle time below the threshold, it would get the fee back.

- A fuel tax targeting diesel would not be fair, as this wouldn't just affect tour buses and delivery vehicles.

- Some vehicles (e.g., with hydraulic lifts) may need to idle to operate their equipment. Delivery companies should be given the opportunity to prove why they need to idle and would then get an exemption sticker.

Police officers could ensure compliance, or tour companies could install GPS devices that record engine idle time, as is already done on GPA vehicles.

Responsible for coordinating implementation:

Joe Santos and Cyrus Luhr

\section{Potential challenges}

This strategy is initially investigative in nature. The likelihood of encountering obstacles will be determined at the point that draft legislation is shown to legislators. If they are very resistant, it could be helpful to educate them on the potential advantages.

\section{Specific actions and timeline}

1. Establish the number of tour buses and other heavy vehicles on Guam to determine the extent of the problem.

2. Talk to tour companies to find out if they have calculated the cost of idling a bus. What does an hour of idling time translate into in terms of miles traveled or specific maintenance costs. [Joe Santos]

3. Draw up sample legislation and show it to legislators to see what the response is likely to be. [Cyrus Luhr]

13 I P a g e 


\section{Reporting on progress and measuring impact}

Joe Santos and Cyrus Luhr will report progress at the general GETF meeting scheduled for June 14, 2013.

\section{B. Investigate the Pricing Structure for Vehicle Registration Fees}

Fuel economy and emissions are related. If an engine is not tuned correctly, uncombusted fuel goes out the tailpipe as particulate emissions. There are currently no emissions tests on Guam.

Vehicle registration fees are currently very low. The GETF will investigate the possibility of:

- Raising the fees significantly but provide a discount on registration fees for low-emissions vehicles or vehicles that get high miles per gallon. (The definition of "low emissions" and "low fuel consumption" will be clarified as part of the task.)

- Imposing a one-time fee at the time of purchase for vehicles with high fuel consumption.

- Using energy savings to encourage additional energy savings, e.g., mandating that all fees collected go into a revolving energy fund that the government can't tap into for other purposes.

In Guam, power plant emissions fees are paid based on the type of pollutant and the amount of each pollutant emitted. It might be possible to mirror this fee structure with prospective vehicle emissions standards.

Investigate the pricing structure for vehicle registration fees to see if (1) the base registration fees should be increased, (2) new fees should be added to change behavior.

\section{Responsible for coordinating implementation: Joe Santos and Cyrus Luhr}

\section{Potential challenges}

This strategy is initially investigative in nature. The likelihood of encountering obstacles will be determined at the point that draft legislation is shown to legislators. If they are very resistant, it could be helpful to educate them on the potential advantages.

\section{Specific actions and timeline}

1. Investigate the current pricing structure for vehicle registration fees in other states and do a literature search on the impact of registration fees on buying habits.

2. Estimate the likely impact in Guam of (1) increasing the base registration fees, and (2) adding other fees.

3. Draw up example legislation and show it to legislators to see what the response is likely to be.

[Cyrus Luhr]

\section{Reporting on progress and measuring impact}

Joe Santos and Cyrus Luhr will report progress at the general GETF meeting scheduled for June 14, 2013. 


\section{Examine the Feasibility of Bringing Electric Vehicles to Guam}

Electric vehicles (EVs) use much less fossil fuel than traditional vehicles, getting in excess of 100 miles per gallon equivalent (MPGe). If electricity is generated from fossil-fuel sources, EVs still use some fossil fuel, but switching the vehicle fleet to EVs could have a large impact on Guam's fossil-fuel use in the long term.

EVs have the advantage of having an onboard energy storage system (their batteries) that in some cases can be used to help stabilize intermittent power production/demand, during periods when the vehicles are plugged into the grid. Adopting EVs could thus serve two purposes.

While widespread importation of EVs is clearly a long-term goal, it might be possible to develop a pilot project through GPA or DPW to test the feasibility of using EVs in Guam. Guam has very consistent temperatures year-round, and has shorter driving distances and shorter driving times than the mainland, all of which significantly extend the overall life of EV batteries.

\section{Responsible for coordinating implementation: Allison Rutter}

\section{Potential challenges}

This strategy is entirely investigative in nature and is not likely to face any obstacles.

\section{Specific actions and timeline}

1. Conduct a literature search of existing EV studies. [Allison Rutter]

2. Evaluate how the results of these studies need to be modified/tailored for Guam. [Allison Rutter and James Thomas]

3. Investigate existing tax incentives for purchasing EVs. [Allison Rutter and James Thomas]

4. Identify funding for an RFP to develop a Guam-specific study on (1) EV fleets, and (2) using EVs for grid buffering, to establish the likely impact on fossil-fuel consumption in Guan. [Joaqin Flores and John Cruz will lead, James Thomas will provide technical input]

\section{Reporting on progress and measuring impact}

Allison Rutter will report progress at the general GETF meeting scheduled for June 14, 2013. 


\section{APPENDICES}

\section{A.1. Guam Energy Task Force Members and Other Contributors to the Action Plan}

\section{Peter Calvo}

\section{Co-Chair, Guam Energy Task Force}

Director, Guam Energy Office

Reviews energy consumption on Guam, working to maximize energy conservation and efficiency, promote renewables and alternative sources of energy locally. Expedites and directs required activities to encourage energy awareness and programs.

\section{Robert A. Underwood}

\section{Co-Chair, Guam Energy Task Force}

\section{Tom Ada}

Senator, 32nd Guam Legislature

Responsible for formulating, introducing, and advocating the passage of legislation. Chairman of the Committee on Public Safety, Infrastructure, and Marine Transportation

\section{Heidi Ballendorf}

Public Affairs Director, Consolidated Commission on Utilities, Guam Power Authority

Responsible for all external messaging for both the GPA and GWA as well as the Governing Body, the CCU.

\section{Anthony Barcinas}

\section{Rudy Bautista}

\section{Laura Biggs}

Assistant Professor of Extension and Education Services, University of Guam Sea Grant Program

Focuses on Sea Grant program development in addition to education and extension program design and implementation. Education and extension programs serve the needs of the community in four main areas: hazard resilience, healthy coastal ecosystems, sustainable development and safe, sustainable seafood supply.

\section{Dan Cook}

Commander, United States Navy, Civil Engineer Corps

Serves as the Assistant Regional Engineer (J44) in Joint Region Marianas, Guam, assigned to NAVFAC Marianas, providing leadership and programmatic direction in the execution of over $\$ 280$ million of installation support funding to Naval Base Guam and Andersen Air Force Base. Commander Cook manages the region's energy program and leads infrastructure investment efforts.

\section{John J Cruz, Jr.}

Manager, Strategic Planning \& Operations Research Division (SPORD), Guam Power Authority Oversees GPA's smart grid program, renewable energy acquisition, large customer demand-side management programs, fuel planning and contracting, outsourcing, strategic and business planning, integrated resource and other longrange planning.

\section{Peggy Denney}

Program Administrator, $i *$ recycle

Promotes the recycling of aluminum beverage containers for the financial benefit of Guam's schools, working for seven local companies that created this nonprofit program. Promotes zero waste at major events and works with 
government agencies, businesses, organizations and others in order to increase the amount of waste being diverted from the Layon landfill.

Joseph M. Diego

Area Director, USDA Rural Development

Oversees Agency mission responsibilities for Guam, the CNMI, Republic of Palau and the Republic of the Marshall Islands, reporting to the State Director located at the State Office in Hilo, Hawaii.

\section{Joaquin C. Flores}

General Manager, Guam Power Authority

In 2005, Mr. Flores was appointed General Manager of the Guam Power Authority. Since then, he has been instrumental in charting the Authority's new direction forward to acquire renewable energy technologies through an integrated resource plan, managed the Authority's effort to regain investment grade and the inclusion of SMART Grid technology within the Authority's power grid. Mr. Flores recently presented to the Consolidated Commission on Utilities a recommendation to identify liquefied natural gas as an alternative energy resource in place of existing fuel-oil-fired steam engines.

\section{Bruce Fredrick}

General Manager, Utilities Services Specialists, Inc.

\section{William H. Hagen}

Owner, Pacific Solar \& Photovoltaics, Inc.

\section{John Heckmann}

\section{Lucy Kono}

Administrative Officer, Guam Energy Office

Coordinates and administers all federal grants that are awarded to GEO. Ensures compliance with federal rules and regulation on all grants awarded to GEO. Reports financial and activity performance on all grants awarded to GEO to US Dept. Of Energy and OMB.

\section{Cyrus Luhr}

Senior Policy Analyst, Office of Senator Thomas C. Ada

Develops policies and legislation. Manages research and reports for the Committee on Public Safety, Infrastructure \& Maritime Transportation.

\section{Michael Makio}

Principal Architect and LEED AP, Taniguchi Ruth Makio Architects

A University of Oregon graduate and one of the first island professionals to achieve LEED Accredited Professional (AP) status, Michael is the principal architect for the first LEED Gold certification on Guam (GCC Learning Resource Center) and the first commercial LEED Gold certification (for the Coast 360 Federal Credit Union). Michael currently has three design projects undergoing LEED Certification and designed energy efficiency upgrades for 52 GovGuam facilities as part of the ARRA program.

\section{Desiree Masterson}

Regional Energy Program Manager, US Navy, Joint Region Marianas

The Energy Program Manager for all Navy and Air Force facilities on Guam. Coordinates with the installations to develop plans and strategies to meet Federal, DoD and Navy energy and water goals and mandates. Serves as the Regional Subject Matter Expert for facilities energy issues.

\section{Dr. Unaisi Nabobo-Baba}

Professor of Education, University of Guam, Chair Admin/Supervision 
Artemio S Perez

John Peterson

Assistant Vice President, University of Guam

Graduate Studies and Office of Sponsored

Research Programs

\section{Edwin Reyes}

Sustainability Coordinator, University of Guam, Center for Island Sustainability

Point of Contact for the Center for Island Sustainability, UOG Green Initiative Coordinator and Coordinator of Education and Outreach.

\section{Allison Rutter}

Principal, Guam Sustainability Solutions, LLC

Allison Rutter helps architects, building owners, contractors and communities create highly efficient buildings that save both energy and money. As a former member of Rocky Mountain Institute's LEED Certification Team, Allison reviewed and approved LEED projects for certification by the US Green Building Council. Allison holds a BS in Mechanical Engineering and is a licensed Professional Engineer in the state of Colorado.

\section{Joseph Santos}

\section{Gabriel Simon}

Director of Engineering Development, P. H. R. Ken

Micronesia, Inc.

Engineering oversight for the Ken Corp holdings on Guam: the Sheraton, Hilton, Pacific Islands

Club, Hyatt and the Nikko Hotels. Focuses on optimization of engineering systems operation and energy efficiency upgrades. Involved in capital improvements, new construction and renovations. Liaison with government regulatory agencies, and engineering and technical representative for Ken Corp.

\section{Carl Swanson}

\section{James R. Thomas}

\section{Elvie Tyler}

Sustainability Coordinator, University of Guam, Center for Island Sustainability

Point of Contact for the Center for Island Sustainability, UOG Green Initiative Coordinator and Coordinator of Education and Outreach.

\section{Aline Yamashita \\ Brent Wiese}

Chairman, Guam Building Code Council (GBCC)

GBCC was charged by the Legislature to create an energy code for Guam. The Guam Tropical Energy Code should soon be approved for use on island. Brent has over 30 years of architectural experience and is currently an Architect and Principal with RIM Architects (Guam), LLC. Brent is LEED AP BD+C certified. 


\section{A.2. Fossil Fuel Consumption Scenarios: Wedge Analysis}

The purpose of this "wedge" analysis is to show, in graphical form, the likely impact of measures taken to reduce the use of fossil fuels. After an alternative technology or policy is implemented, it creates an irregular-looking wedge on the graph, hence the name given to this type of analysis.

\section{General Methodology and Assumptions}

The wedge analysis for Guam was performed by NREL using information provided by the Guam Power Authority and other official sources. The first wedge analysis was developed for Guam's strategic energy plan using 2010 data. That analysis established a business as usual (BAU) or base case against which the impact of any actual and proposed changes to Guam's energy consumption patterns can be compared. Those changes could be the result of energy efficiency measures, energy conservation, or expanded use of alternative power-generation technologies.

Energy can be measured using a variety of units, such as kilowatt-hours or kWh (for electricity) and British thermal units or Btu's (for heat energy). Units of energy can readily be converted into each other.

As this action plan focuses on fossil-fuel reduction, the analysis illustrates the consumption of electricity in barrels of oil equivalent (BOE) through 2020, a unit of measure that indicates how many barrels of oil would need to be consumed to meet the demand for energy. The number of Btu's in a barrel of oil is calculated for each year from data supplied by GPA and varies depending on the particular mix of fuel oil consumed by GPA that year.

\section{Base Case}

In the base case (figure 3), it is assumed that no significant steps are taken to curb fossil fuel use. In this scenario, energy consumption is projected to grow at a linear rate of $0.119 \%$ per year from 2010 onwards. That growth rate is calculated from utility data on actual consumption patterns from 2000 to 2010. This BAU scenario also assumes no major fluctuations in fuel prices by incorporating the average fuel cost for the period from 2000 to 2010.

The base case graph is a solid blue color, reflecting the fact that Guam's electricity is generated mainly from fossil fuels. 


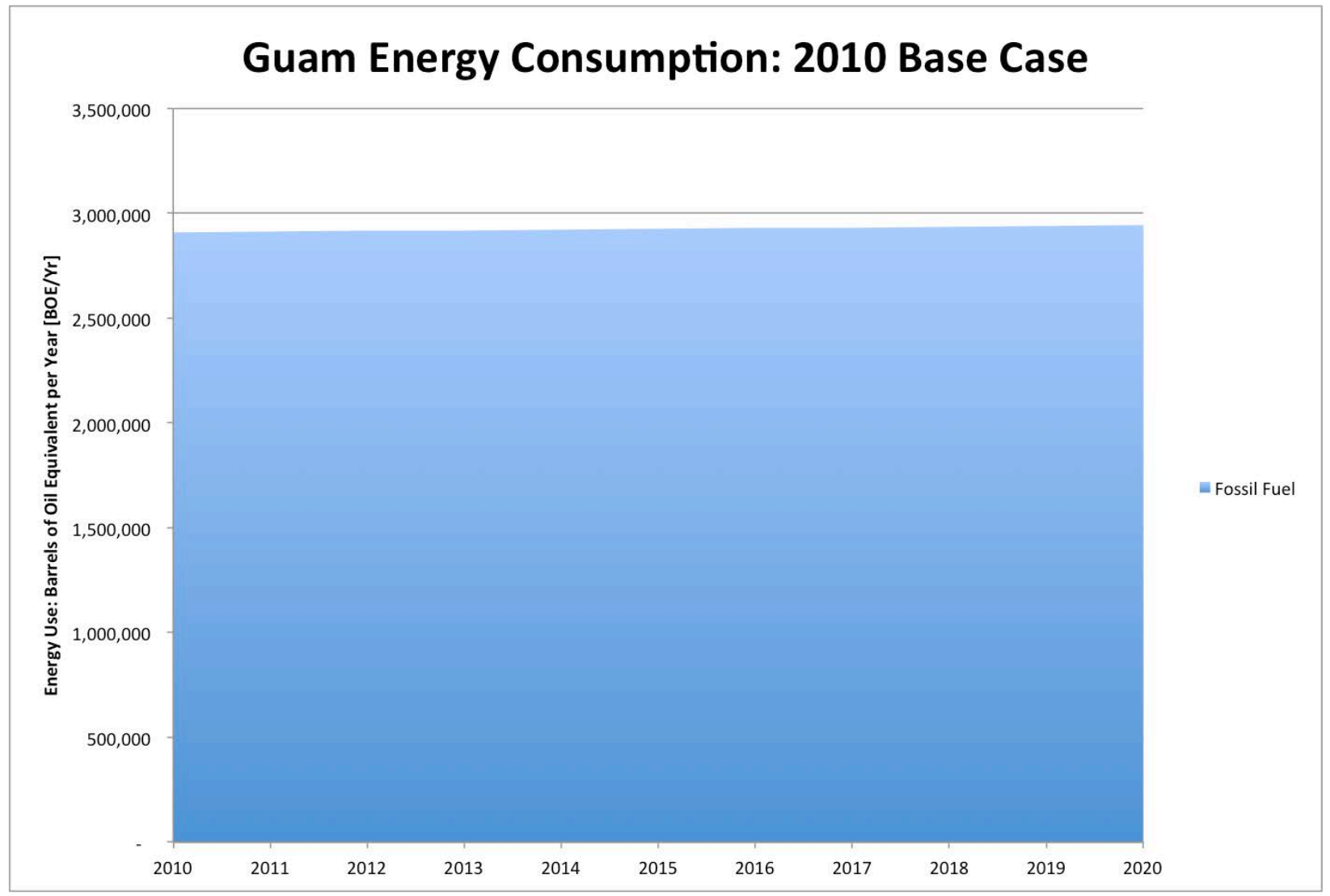

Figure 3. Energy consumed to generate electricity: 2010 base case

\section{Future Scenario}

In the future scenario (figure 4), the overall shape of the graph reflects the same growth in total energy consumption $(0.119 \%$ per year $)$ as the base case. The graph has been updated with actual energy consumption and generation data from 2010 to 2012. The purple area at the top of the graph shows the drop in energy demand during those two years.

Projected data is used for the period from 2012 to 2020. Future projections can derive from communication and published information from GPA and other official sources regarding planned conversion of electricity generators to LNG, legally binding contracts or laws governing additions of renewable energy generation to the electricity grid, the anticipated impact on energy demand of energy efficiency and conservation measures stemming from this action plan, and the latest information on the likely impact of military personnel on Guam's energy consumption.

The actual criteria included in the future projection are described in the methodology and assumptions section below the graph. The actual energy demand in 2012 is projected forward to 2020 as a fixed percentage of the total BAU energy demand, which means that the thickness of the "demand reduction" wedge is a fixed proportion of BAU demand.

Both actual and projected data can be updated each year as more information becomes available. 
The future scenario graph shows an expanding wedge of renewable energy generation replacing fossil fuel generation starting shortly after 2012. This wedge is primarily the result of Public Law 29-62, which requires that $5 \%$ of net electricity sales come from renewable sources by the end of 2015 . The scenario does not currently include any energy efficiency actions.

Because of inefficiencies in the process of power generation and transmission as well as other system losses, approximately $1.136 \mathrm{MWh}$ of electricity must be produced for every $1 \mathrm{MWh}$ of electricity that is sold.

Replacing $5 \%$ of electricity sales from fossil-fueled generators with electricity from renewable resources would lead to a $136,146 \mathrm{bbl}^{2}$ reduction in fossil fuel consumption in Guam, saving approximately $\$ 15$ million per year in fuel costs.

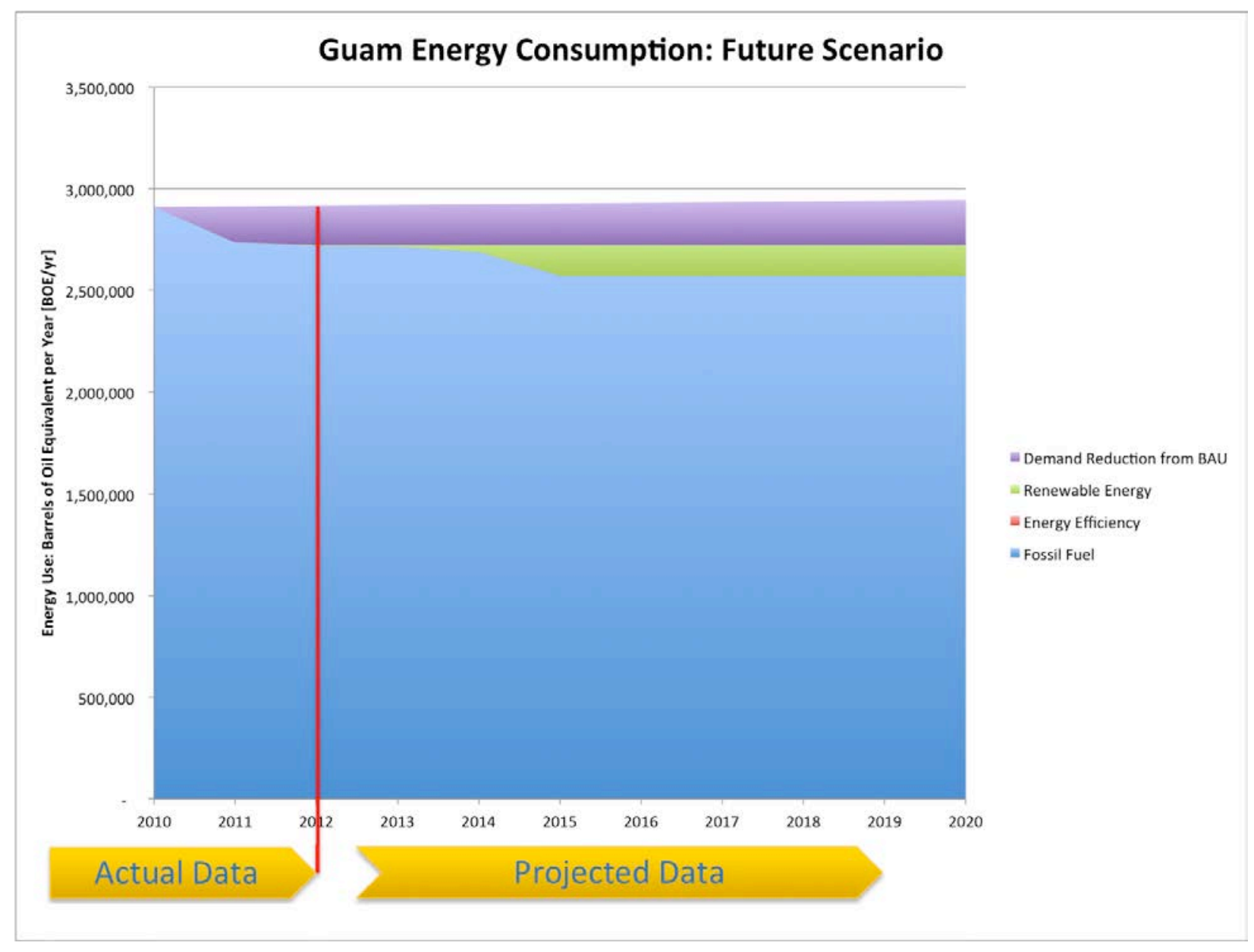

Figure 4. Energy consumed to generate electricity: actual and projected

${ }^{2}$ barrels

21 | $\mathrm{P}$ a g e 
Methodology and Assumptions for the Future Scenario

This section walks through the key calculations used to develop the graph in figure 4 .

\section{Assumptions Included in the Future Scenario}

- According to Public Law $29-62,5 \%$ of net electricity sales must come from renewable sources by December 31, $2015^{3}$

- These sales are assumed to derive from the following:

- $429 \mathrm{kWh}$ from net-metered wind and PV systems ${ }^{4}$

- $\quad 9.35 \mathrm{MW}$ of wind generating capacity from Pacific Green Resources LLC projects

- Additional unspecified projects required to reach the goal of $5 \%$ of net electricity sales generated by 2015 .

Included in the 2013 GPA integrated resource plan, but not included in wedge analysis due to the absence of an accepted RFP or a firm implementation plan (may be included in the wedge analysis at a future date):

- $10 \mathrm{MW}$ geothermal plant planned for 2019

- $60 \mathrm{MW}-120 \mathrm{MW}$ combined-cycle gas power plant

\section{Calculation of Fuel Savings from Renewable Energy}

Calculations begin with the assumption that $5 \%$ of net electricity sales come from renewable energy by 2015 and use 2012 as the baseline year.

The following data was provided by the utility:

\begin{tabular}{|l|r|r|r|}
\hline \multicolumn{4}{|c|}{ 2012 Fuel Consumption Data } \\
\hline \multicolumn{1}{|c|}{ Fuel } & \multicolumn{1}{|c|}{$\begin{array}{l}\text { Units } \\
\left(\mathbf{b b |}^{\mathbf{5}}\right)\end{array}$} & \multicolumn{1}{c|}{ Costs } & \multicolumn{1}{c|}{$\begin{array}{c}\text { Million Btu } \\
\text { (MMBtu) }\end{array}$} \\
\hline High Sulfur RFO & $1,928,688$ & $\$ 212,876,225$ & $12,150,734$ \\
\hline Low Sulfur RFO & 734,015 & $\$ 78,093,042$ & $4,624,295$ \\
\hline Ultra Low Sulfur Diesel & 60,208 & $\$ 9,095,427$ & 351,494 \\
\hline TOTALS & $2,722,911$ & $300,064,694$ & $17,126,523$ \\
\hline
\end{tabular}

\footnotetext{
${ }^{3} \mathrm{http}: / /$ www.guampdn.com/article/20130423/NEWS01/304230310/Wind-turbine-added-University-Guam, accessed April 24, 2013

${ }^{4}$ Email to NREL from GPA.

${ }^{5}$ barrels
}

22 | P a g e 


\begin{tabular}{|l|r|}
\hline \multicolumn{2}{|c|}{ 2012 Fuel Cost Data } \\
\hline \multicolumn{1}{|c|}{ Fuel Type } & \multicolumn{1}{c|}{ Cost [\$/bbl] } \\
\hline High Sulfur RFO & 110.37 \\
\hline Low Sulfur RFO & 106.39 \\
\hline Ultra Low Sulfur Diesel & 151.07 \\
\hline
\end{tabular}

\begin{tabular}{|l|r|}
\hline \multicolumn{2}{|c|}{2012 Fuel Generation Data } \\
\hline Total Electricity Generation [MWh] & $1,784,446$ \\
\hline Total Net Electric Sales [MWh] & $1,570,396$ \\
\hline Generation Efficiency (Heat Rate) [MMBtu/MWh] & 10.145 \\
\hline
\end{tabular}

In 2012, GPA generated 1,784,446 MWh of electricity, of which 1,570,396 MWh was sold.

The ratio of generated power to net sales can be used to derive a single number that summarizes the approximate transmission and distribution system losses, losses in the electricity generating process and other losses associated with the avoided energy generation:

\section{1,784,446 generated $\mathrm{MWh} / 1,570,396$ sold $\mathrm{MWh}$ \\ = 1.1363 generated $\mathrm{MWh} /$ sold $\mathrm{MWh}$}

In other words, $1.1363 \mathrm{MWh}$ is generated for every $1 \mathrm{MWh}$ sold.

To calculate $5 \%$ of net electricity sales:

$$
1,570,396 \mathrm{MWh} * 0.05=78,520 \mathrm{MWh}
$$

To calculate the fuel savings from a $5 \%$ reduction in electricity consumption:

It seems reasonable to assume a linear relationship between electricity consumed and electricity generated. It also seems reasonable to assume a linear relationship between electricity generated and the fuel used to generate that electricity. The model is evaluating electricity generation (and fuel savings) at the margin, and there is no reason to assume that power plant efficiency will be impacted significantly by an incremental reduction in power plant output.

Thus a $5 \%$ reduction in electricity sales results in a $5 \%$ reduction in electricity generation and a $5 \%$ reduction in fossil fuel consumption for power generation.

Total fuel consumed by GPA for electricity production in 2012 was 2,722,911 bbl. The projected fuel savings from a $5 \%$ reduction in electricity consumption is thus:

$$
2,722,911 \mathrm{bbl}^{*} 0.05=136,146 \mathrm{bbl}
$$


To calculate the dollar value of the fuel savings:

The weighted average cost of fuel is calculated using the following information provided by GPA. The weighting of each fuel is calculated as the percentage of individual fuel type relative to the total barrels of oil purchased.

High Sulfur RFO: $70.83 \%$

Low Sulfur RFO: $26.96 \%$

Ultra Low Sulfur Diesel: $2.21 \%$

The weighted average cost $\left(C_{w}\right)$ is then calculated as:

$$
\begin{aligned}
C_{w} & =(\$ 110.37 * 0.7083)+(\$ 106.39 * 0.2696)+(\$ 151.07 * 0.0221) \\
& =\$ 110.20 / \mathrm{bbl}
\end{aligned}
$$

The fuel cost savings (rounded to the nearest dollar) is calculated using the projected fuel savings and the weighted average cost of fuel for 2012:

$$
136,146 \mathrm{bbl} * \$ 110.20 / \mathrm{bbl}=\$ 15,003,289
$$




\section{A.3. Glossary of Energy Management Concepts}

Demand-side management (DSM) - Actions undertaken by a utility to change the level or timing of energy use on the customer side of the electricity meter, generally with the intention of optimizing existing and planned generation and transmission assets on the utility side of the meter. It encompasses utility-initiated actions to improve energy efficiency, increase energy conservation, and reduce peak electricity demand. Examples include rebates, incentives and utility investments that improve building shell insulation and the efficiency of heating and cooling systems, and rate structures that shift demand from times of peak energy use to off-peak hours.

DSM includes other load management approaches, such as direct load control systems that enable the grid operator to regulate the electricity used by individual appliances or equipment on customer premises (usually residences), and contractual arrangements that allow the utility to reduce demand by specific customers (usually businesses) through direct action by the grid operator (remote tripping) or by the customer voluntarily taking action to reduce demand when requested by the grid operator.

DSM is sometimes defined to include utility incentives to encourage electricity generation by customers, because it reduces the need for the utility to invest in power plants or transmission and distribution networks. This definition of DSM includes solar photovoltaic (PV) or other distributed generation systems installed on a customer's property, but does not include PV or other distributed generators installed on the transmission or distribution grid.

DSM refers only to energy and load-shape modifying activities that are undertaken in response to utilityadministered programs, such as a utility incentive to customers encouraging them to buy more energyefficient light bulbs. It does not refer to changes arising from normal operation of the market (such as the independent decision by a customer to buy such light bulbs because electricity is expensive) or from government-mandated energy efficiency standards.

Energy conservation - The process of using less energy by reducing or going without a service. Energy conservation typically requires a change in behavior or not using an existing technology, e.g., turning off a light, using the stairs instead of taking the elevator, or turning up the thermostat on an air conditioner. Popular approaches to accomplishing energy conservation goals include: (1) educating people about how to conserve energy, and (2) implementing nonenergy-consuming technologies such as cool roofs, which reduce the need for air conditioning.

Energy efficiency - The process of using less energy to provide the same service, or using the same amount of energy to provide more services. Energy efficiency typically requires the use of a different energy technology or using existing technology in a different way. For example, a compact fluorescent light (CFL) or light-emitting diode (LED) bulb is more energy efficient than a traditional tungsten incandescent light bulb because it produces the same amount of light (measured in lumens) using significantly less electrical energy.

Supply-side management - Refers to the practice of electric utilities building generating plants to serve whatever demand customers require. This practice was the norm until the 1970s. 


\section{PHOTO CREDITS}

Front cover: top-left image is by Peter McNutt, the other images are by Eliza Hotchkiss.

Back cover (left to right): PIX 17613, PIX 16694, PIX 10891, PIX 08022, Judy Powers. 
NATIONAL RENEWABLE ENERGY LABORATORY — LEADING CLEAN ENERGY INNOVATION

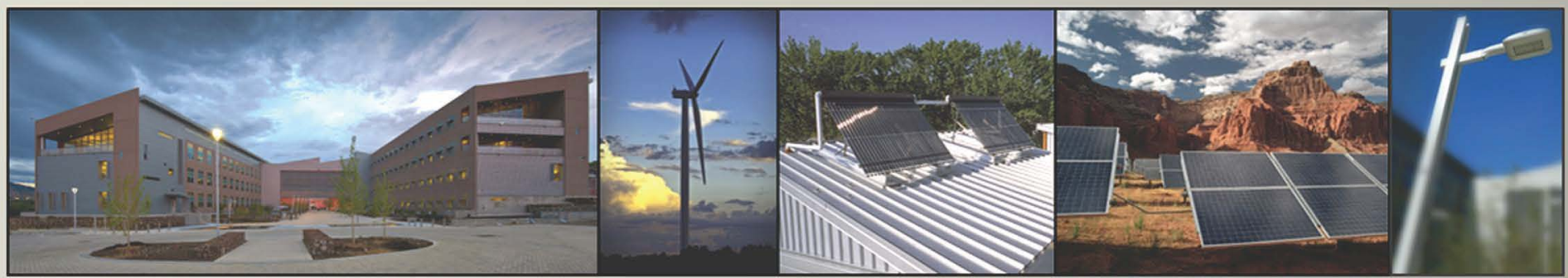

Prepared by the National Renewable Energy Laboratory (NREL), a national laboratory of the U.S. Department of Energy, Office of Energy Efficiency and Renewable Energy, operated by the Alliance for Sustainable Energy, LLC. NREL is the U.S. Department of Energy's primary laboratory for renewable energy and energy efficiency research and development.

15013 Denver West Parkway, Golden, CO 80401 + 303-275-3000 + www.nrel.gov 